\title{
Recrystallization-Precipitation Interaction Study of Two Medium Carbon Niobium Microalloyed Steels
}

\author{
S. F. MEDINA, A. QUISPE, P. VALLES ${ }^{1)}$ and J. L. BAÑOS ${ }^{2)}$
}

Centro Nacional de Investigaciones Metalúrgicas (CENIM-CSIC), Av. Gregorio del Amo, 8; 28040, Madrid, Spain. 1) Instituto Nacional de Técnica Aeroespacial (INTA), Torrejón de Ardoz, Madrid, Spain.

2) Facultad de Odontología, Dpto. Estomatología II, UCM, Madrid, Spain.

(Received on January 21, 1999; accepted in final form on June 18, 1999)

\begin{abstract}
Recrystallization-precipitation-time-temperature (RPTT) diagrams for strains of 0.20 and 0.35 have been determined for two microalloyed steels with niobium percentages of 0.024 and 0.058 , respectively, and equal percentages of carbon and nitrogen. The method known as "back extrapolation" has been used for the determination of static recrystallization kinetics and also for the plotting of the diagrams. While a single plateau was observed on the recrystallized fraction against time curves for the first steel, as a consequence of strain induced precipitation, these curves for the second steel showed the formation of a double plateau, whose interpretation, confirmed by calorimetric analysis, supposes the formation of two types of precipitates. The work uses transmission microscopy to show the precipitates which are formed in both steels, as well as the size most probably capable of inhibiting recrystallization. Finally, an analysis is made of the RPTT diagrams and of the large amount of information which they offer for designing a more appropriate rolling schedule in order to obtain finer precipitates and a better austenitic microstructure before the austenite $\rightarrow$ ferrite transformation.
\end{abstract}

KEY WORDS: static recrystallization; precipitation; RPTT diagrams; electron transmission microscopy.

\section{Introduction}

Most hot rolled microalloyed steels are steels which contain niobium, as these have the advantage of adequate solubility at normal rolling temperatures. Vanadium presents greater solubility in austenite than niobium and its precipitation as VN, and above all as VC, occurs at very low temperatures, making it difficult to obtain sufficiently deformed austenites before the $\gamma \rightarrow \alpha$ transformation. To this end, a good part of the research work on microalloyed steels has been focused on low or medium carbon niobium steels, obtaining highly deformed austenites at the end of rolling which give rise, after the transformation, to very fine ferrite/pearlite microstructures and consequently good mechanical properties.

However, $\mathrm{Nb}$ microalloyed steels should not be considered to be the ideal steels, as they present some disadvantages which make it difficult to finally obtain fine precipitates in hot rolling. On the one hand, in steels with a $\mathrm{C}$ content of approximately $0.2 \%$, around $60 \mathrm{ppm}$ of $\mathrm{N}$, the difference between the solubility temperatures of niobium carbides and carbonitrides are not very different. $^{1-4)}$ One of the consequences deriving from the above is the formation of complex carbonitrides which can be formed not as a precipitate as such but by the heterogeneous nucleation of one type of precipitates on another, forming relatively complex and coarse pre- cipitates. On the other hand, the precipitation start temperature is relatively high and diffusion is still important for favouring both heterogeneous precipitation and coalescence between precipitates.

With regard to the static recrystallization of these steels, $\mathrm{Nb}$ is known to be the alloying element which most delays kinetics, even when it is in solution. ${ }^{5-10)}$ Its greater atomic volume, compared with other typical alloying elements of low alloy steels, contributes to considerably increasing the activation energy even when it is present only in thousandths. ${ }^{11)}$ Physically, the activation energy for static recrystallization practically coincides with the self-diffusion energy of iron at the grain boundaries, clearly affected by the presence of solutes and above all by precipitates. ${ }^{1-13 \text { ) }}$

When strain induced precipitation starts, static recrystallization is inhibited during a certain time, normally until the end of precipitation, before again advancing until recrystallization is complete. This momentary inhibition of recrystallization appears as a plateau on the recrystallized fraction against the logarithm of time curves. ${ }^{14,15)}$ The good definition of the plateau permits the plotting of the recrystallization-precipitation-timetemperature (RPTT) curves and consequently a greater knowledge of the conditions (temperature, strain, etc.) which permit the obtainment or improvement of the microstructure of these steels. ${ }^{16)}$

Very few experimentally determined RPTT diagrams 
Table 1. Chemical compositions (mass\%) of the steels studied.

\begin{tabular}{|c|c|c|c|c|c|c|c|c|c|}
\hline Steel & $\mathrm{C}$ & $\mathrm{Si}$ & $\mathrm{Mn}$ & $\mathrm{P}$ & $\mathrm{S}$ & $\mathrm{N}$ & $\mathrm{O}$ & $\mathrm{Al}$ & $\mathrm{Nb}$ \\
\hline $\mathrm{N} 3$ & 0.21 & 0.18 & 1.08 & 0.023 & 0.014 & 0.0058 & 0.0040 & 0.007 & 0.024 \\
\hline $\mathrm{N} 4$ & 0.21 & 0.19 & 1.14 & 0.023 & 0.015 & 0.0061 & 0.0046 & 0.008 & 0.058 \\
\hline
\end{tabular}

have been published, though PTT diagrams can be found in the literature determined by theoretical equations, ${ }^{17-21)}$ transmission microscopy ${ }^{22)}$ stress relaxation methods, ${ }^{23.24)}$ and finally by applying the "back extrapolation" method. ${ }^{16)}$

The temperature at which the inhibition of recrystallization starts has been termed the Static Recrystallization Critical Temperature (SRCT) and its difference from the No-Recrystallization Temperature $\left(T_{\mathrm{nr}}\right)$ has been discussed elsewhere. ${ }^{25)}$

In this paper the static recrystallization-precipitation interaction is studied in two niobium microalloyed steels through the determination of RPTT diagrams. An analysis is made of the influence of the strain on this interaction and transmission electron microscopy (TEM) is used to assess the size, distribution, nature and coalescence of the precipitates.

\section{Experimental Procedure}

The steels used, and referred to as N3 and N4, were manufactured by Electroslag Remelting (ESR) in a laboratory unit capable of producing $30 \mathrm{~kg}$ ingots. Their compositions are shown in Table 1. This technique avoids macrosegregation, both in alloying elements and impurities, and there is considerably less microsegregation; these defects being present in conventional ingots and continuous casting billets. The compositions of the two steels differ only in their $\mathrm{Nb}$ contents, the contents of other elements being similar.

The torsion specimens, with a useful length of $50 \mathrm{~mm}$ and $6 \mathrm{~mm}$ in diameter, were austenitized at $1250^{\circ} \mathrm{C}$ for $10 \mathrm{~min}$ and then the temperature was rapidly reduced to the testing temperature and maintained at that temperature for a time of no more than $90 \mathrm{~s}$. During the test the specimens were protected by an argon atmosphere in order to prevent their oxidation.

The magnitudes of torsion (torque, no. of revolutions) and the equivalent magnitudes (stress, strain) have been related in accordance with Von Mises criterion. ${ }^{16)}$ The recrystallized fraction was determined at different temperatures, at the equivalent strains of 0.20 and 0.35 , at a constant strain rate of $3.63 \mathrm{~s}^{-1}(=1000 \mathrm{rev} / \mathrm{min})$. The strains applied were programmed so as to be reached at the surface of the torsion specimen and the microstructures were observed on a lengthways portion near the cylindrical surface.

The recrystallized fraction has been measured using the method known as "back extrapolation". ${ }^{26)}$ It has been found that using this method the softened fraction and the recrystallized fraction are approximately equal. ${ }^{27)}$

The characteristics of the precipitates were determined
Table 2. Solubility temperature $\left(T_{\mathrm{s}}\right)$ of the precipitates, according to Turkdogan's solubility products, ${ }^{2\}}$ for steels used.

\begin{tabular}{|c|c|c|c|}
\hline \multirow{3}{*}{ Steel } & \multicolumn{3}{|c|}{ Solubility temperature $\mathrm{T}_{\mathrm{s},} \mathrm{K}\left({ }^{\circ} \mathrm{C}\right)$} \\
\cline { 2 - 4 } & {$[\mathrm{Nb}][\mathrm{C}]^{0.8^{n}}$} & {$[\mathrm{Nb}][\mathrm{N}]$} & {$[\mathrm{Nb}][\mathrm{C}]^{0.7}[\mathrm{~N}]^{0.2}$} \\
\hline $\mathrm{N} 3$ & 1399 & 1327 & 1419 \\
& $(1126)$ & $(1054)$ & $(1146)$ \\
\hline $\mathrm{N} 4$ & 1514 & 1402 & 1506 \\
& $(1241)$ & $(1129)$ & $(1233)$ \\
\hline
\end{tabular}

Table 3. Transformation temperatures $\mathrm{Ac}_{1}, \mathrm{Ac}_{3}$ and $\mathrm{Ar}_{3}$ at heating rate and cooling rate of $0.25^{\circ} \mathrm{C} / \mathrm{s}$ and grain size $\mathrm{D}_{\gamma}(\mu \mathrm{m})$ at $1250^{\circ} \mathrm{C} \times 10 \mathrm{~min}$ of the steels studied.

\begin{tabular}{|c|c|c|c|c|}
\hline Steel & $\mathrm{Ac}_{1}, \mathrm{~K}\left({ }^{\circ} \mathrm{C}\right)$ & $\mathrm{Ac}_{3}, \mathrm{~K}\left({ }^{\circ} \mathrm{C}\right)$ & $\mathrm{Ar}_{3}, \mathrm{~K}\left({ }^{\circ} \mathrm{C}\right)$ & $\mathrm{D}_{7}$ \\
\hline $\mathrm{N} 3$ & $1006(733)$ & $1103(830)$ & $1041(768)$ & 210 \\
\hline $\mathrm{N} 4$ & $1007(734)$ & $1104(831)$ & $1042(769)$ & 190 \\
\hline
\end{tabular}

by transmission electron microscopy (TEM), using the carbon extraction replica technique.

The phase transformation temperatures were determined by the dilatometry technique. The study of the dissolution of precipitates was carried out by differential thermal analysis, where the heating rate of the samples was $15^{\circ} \mathrm{C} / \mathrm{min}$ and they were protected from oxidation by an argon flow of $3(l / \mathrm{min})$.

\section{Results and Discussion}

The austenitization temperature was chosen taking into account that in this type of steels preliminary reheating to the deformation temperatures must guarantee total dissolution of the precipitates. In this sense, the solubility temperature for carbides, nitrides or carbonitrides (Table 2), hypothetically present in both steels, is below the selected austenitization temperature of $1250^{\circ} \mathrm{C}$.

Quenching the specimen in water and carrying out the subsequent metallographic study, the austenite grain size was determined for each steel, corresponding to the austenitization conditions $\left(1250^{\circ} \mathrm{C} \times 10 \mathrm{~min}\right)$. Applying the linear intersection technique, twenty fields were analysed in each specimen and the average austenite grain sizes were determined, which were $210 \mu \mathrm{m}$ and $190 \mu \mathrm{m}$ for steels N3 and N4, respectively (Table 3). Similarly, the dilatometry technique was used to determine the $\mathrm{A}_{3}$ phase transformation temperatures, both in heating $\left(\mathrm{Ac}_{3}\right)$ and in cooling $\left(\mathrm{Ar}_{3}\right)$, with the hysteresis phenomenon naturally appearing. The values obtained for rates of $0.25^{\circ} \mathrm{Cs}^{-1}$ were as indicated also in Table 3 , it being seen that these are similar, or in fact practically equal, for both steels. The different $\mathrm{Nb}$ content and the slight difference in grain size has not influenced the transformation temperatures. Having determined the transformation temperatures, it is assured that the testing temperatures correspond to the austenite phase, taking into 


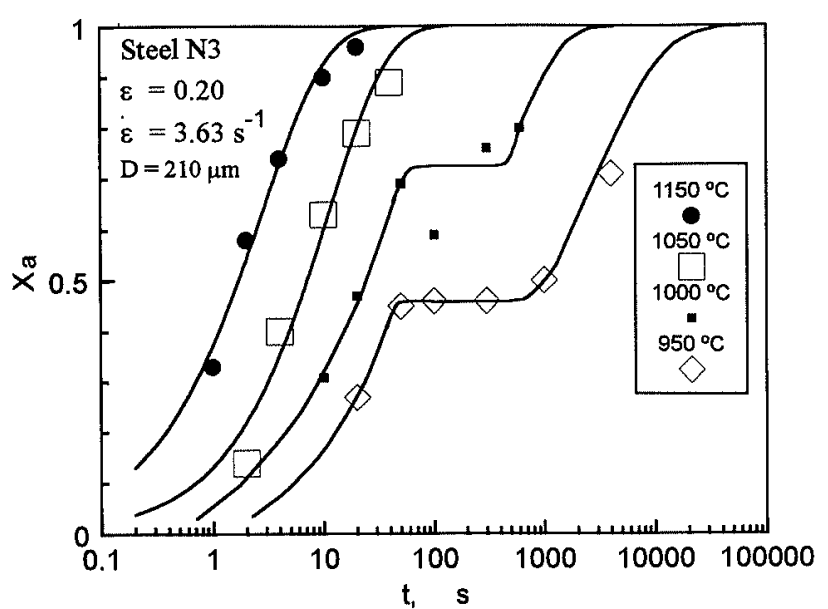

Fig. 1. Variation of the recrystallized fraction $\left(X_{a}\right)$ with time ( $t$ ) for steel $\mathrm{N} 3$ and $\varepsilon=0.20 ; \dot{\varepsilon}=3,63 \mathrm{~s}^{-1}$.

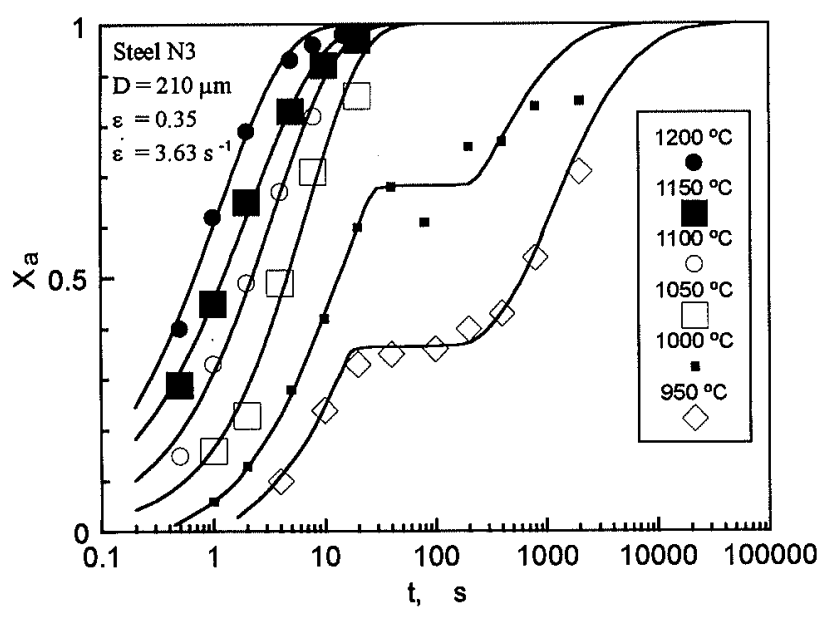

Fig. 2. Variation of the recrystallized fraction $\left(X_{\mathrm{a}}\right)$ with time (t) for steel N3 and $\varepsilon=0.35 ; \dot{\varepsilon}=3,63 \mathrm{~s}^{-1}$.

account furthermore that the $\mathrm{Ar}_{3}$ transformation temperature is a more appropriate reference than $\mathrm{Ac}_{3}$, as both in the torsion tests and in rolling the steel follows a cooling process.

\subsection{Static Recrystallization}

As has been mentioned, the recrystallized fraction was determined for different temperatures and strains of 0.20 and 0.35 , respectively. Figures 1 and $\mathbf{2}$ show the recrystallized fraction against time curves, obtained for steel $\mathrm{N} 3$ and strains of 0.20 and 0.35 , respectively, with the formation being seen of a single plateau on the curves corresponding to $1000^{\circ} \mathrm{C}$ and $950^{\circ} \mathrm{C}$. The shape of the plateau is similar to that which appears in all the microalloyed steels studied to date, both in vanadium, niobium or titanium steels. ${ }^{12,15)}$ The curves corresponding to higher temperatures than those mentioned have the sigmoidal shape of Avrami's law. Furthermore, the plateau is not undefined, i.e. precipitation does not permanently inhibit recrystallization, and recrystallization again progresses until it is complete, following a graphic plot similar to that recorded before the formation of the plateau. This means that before and after the plateau, i.e. before and after precipitation, the recrystallization kinetics obey Avrami's law, whose expres-

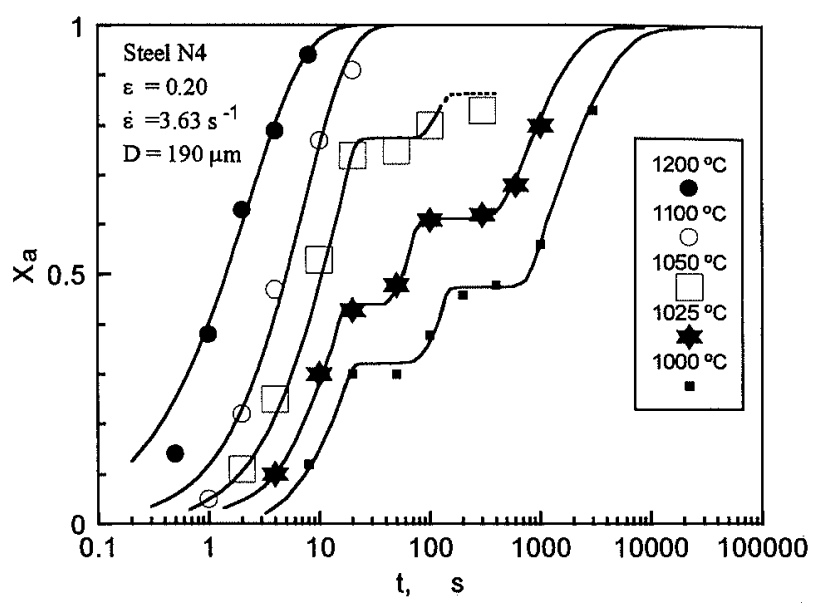

Fig. 3. Variation of the recrystallized fraction $\left(X_{\mathrm{a}}\right)$ with time ( ) for steel N4 and $\varepsilon=0.20 ; \dot{\varepsilon}=3,63 \mathrm{~s}^{-1}$.

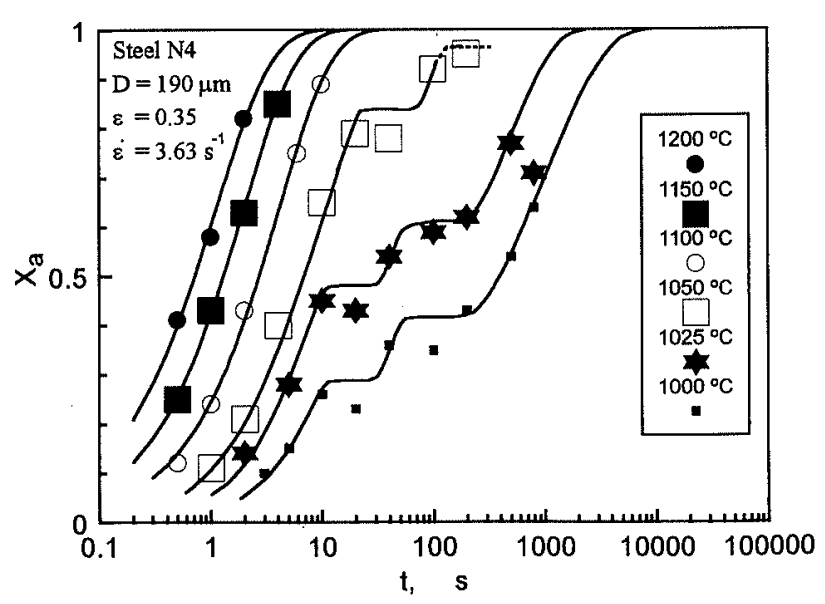

Fig. 4. Variation of the recrystallized fraction $\left(X_{\mathrm{a}}\right)$ with time ( $l$ ) for steel N4 and $\varepsilon=0.35 ; \dot{\varepsilon}=3,63 \mathrm{~s}^{-1}$.

sion is as follows:

$$
X_{\mathrm{a}}=1-\exp \left[-0.693\left(\frac{t}{t_{0.5}}\right)^{n}\right]
$$

where $t_{0,5}$ is the time corresponding to $50 \%$ of the recrystallized volume and depends on the temperature $(T)$, strain $(\varepsilon)$, strain rate $(\dot{\varepsilon})$, grain size $(D)$ and chemical composition of the steel, according to the equation:

$$
t_{0.5}=A \varepsilon^{p} \dot{\varepsilon}^{q} D^{s} \exp \frac{Q}{R T}
$$

where $Q$ is the activation energy, $R=8.3144 \mathrm{~J} \mathrm{~mol}^{-1} \mathrm{~K}^{-1}$, $p, q, \mathrm{~s}, A$ are constants.

When the strain was 0.35 , the recrystallized fraction against time curves for different temperatures were similar to the above, except that recrystallization is now faster, as the strain is greater (Fig. 2).

However, steel N4, unlike the above, presented a double plateau for both strains of 0.20 and 0.35 (Figs. 3 and 4). When the deformation temperature was equal to or less than $1050^{\circ} \mathrm{C}$, the double plateau was formed. In principle, the only possible interpretation of this phenomenon, never before observed, seems to be the formation of two types of precipitates which start to form practically at the same temperature. Once the 


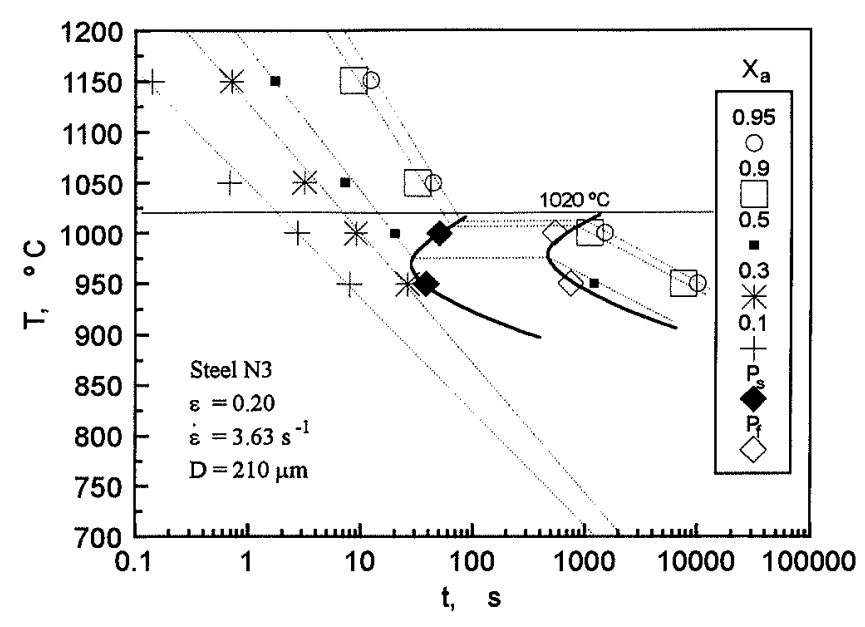

Fig. 5. RPTT diagram for steel N3 and $\varepsilon=0.20$.

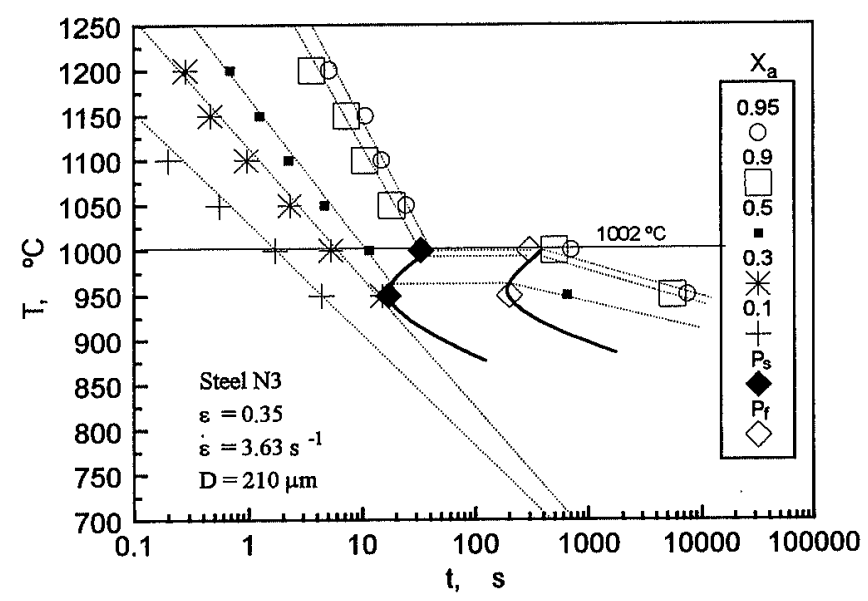

Fig. 6. RPTT diagram for steel $\mathrm{N} 3$ and $\varepsilon=0.35$.

kinetics of the first precipitation (first plateau) ends and recrystallization again continues, the second precipitation starts to occur and once this finalizes recrystallization continues until it is complete. If these results are compared with others previously obtained with low carbon $\mathrm{Nb}$ microalloyed steels, $\mathrm{C}=0.1$ mass $\%,{ }^{9,13)}$ and with steel N3 studied here, a quick glance indicates that the double precipitation takes place when the percentages of $\mathrm{C}$ and $\mathrm{Nb}$ are such as to favour the formation of carbides rather than nitrides. This fact has been corroborated by other results obtained in steels with different percentages of $\mathrm{C}, \mathrm{Nb}$ and $\mathrm{N}$ to those studied here. ${ }^{28)}$

\subsection{RPTT Diagrams}

Figures 1-4 have been used to deduce the temperatures and times which correspond to different recrystallized fractions, such as $0.1 ; 0.3 ; 0.5 ; 0.9$ and 0.95 , as well as the induced precipitation start $\left(\mathrm{P}_{\mathrm{s}}\right)$ and finish $\left(\mathrm{P}_{\mathrm{f}}\right)$ times. In this way we have drawn the RPTT diagrams shown in Figs. 5 and 6, corresponding to steel N3 and strains of 0.20 and 0.35 , respectively. Note that the recrystallized fraction does not vary between the precipitation start $\left(P_{s}\right)$ and finish $\left(P_{f}\right)$ curves and is represented by a horizontal line. Once the $P_{f}$ curve is reached the lines of each recrystallized fraction descend, meaning that as the

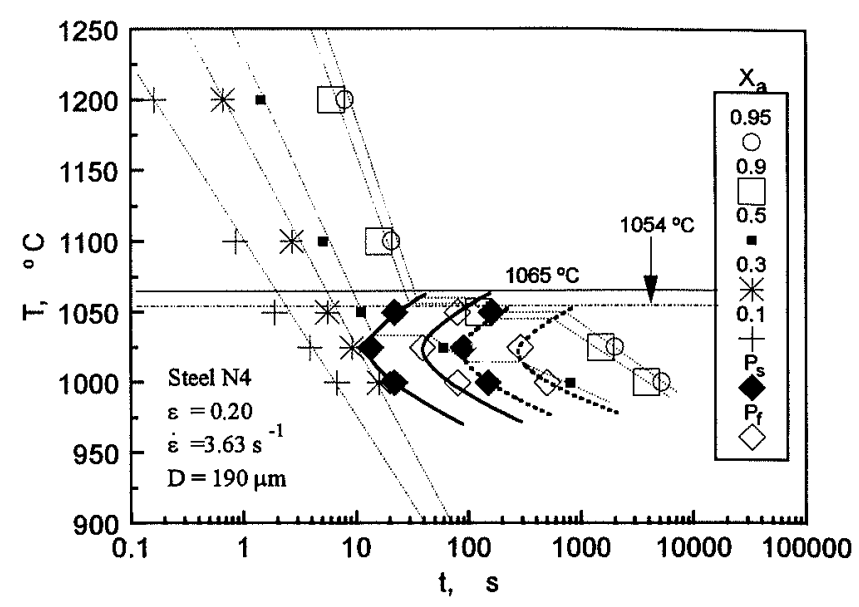

Fig. 7. RPTT diagram for steel N4 and $\varepsilon=0.20$.

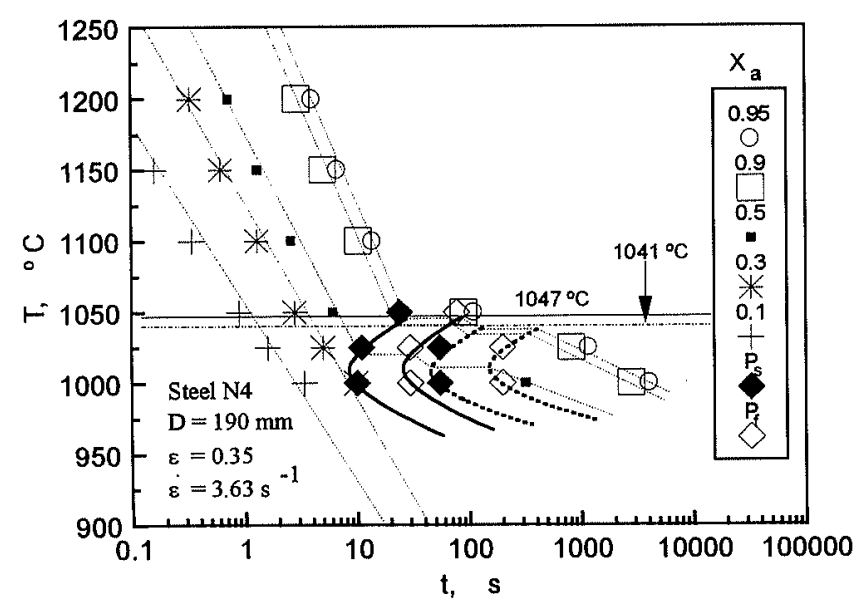

Fig. 8. RPTT diagram for steel $\mathrm{N} 4$ and $\varepsilon=0.35$.

temperature drops more time is necessary to obtain a certain recrystallized fraction after straining. In the case of Figs. 7 and 8 , corresponding to steel $\mathrm{N} 4$, two $\mathrm{P}_{\mathrm{s}}$ curves and two $\mathrm{P}_{\mathrm{f}}$ curves have been drawn, as a consequence of the double precipitation.

An RPTT diagram provides a great deal of information, part of which can be directly read from the diagram itself and another part which must be deduced. With regard to the recrystallization-precipitation interaction, it is seen that the nose of the $P_{s}$ curve, where the incubation time of the precipitates $\left(t_{\mathrm{N}}\right)$ is minimal, the fraction of the volume recrystallized is approximately $50 \%$. When the fraction of volume recrystallized is less than $30 \%$, nucleation of the precipitates does not take place. In other words, for nucleation to be possible it is necessary for the recrystallized fraction to be equal to or greater than $30 \%$.

Precipitation takes place between the $P_{s}$ and $P_{f}$ curves, but once the first precipitates form the phenomenon of coalescence begins, where small precipitates will grow by Oswald ripening. ${ }^{29)}$ It is very difficult to separate the specific contribution of both, precipitation kinetics and coalescence, to the coarsening of the precipitates.

The most important magnitudes which can be deduced from an RPTT diagram, and which are also indispensable for the perfect configuration of the diagram, are the pre- 
Table 4. Temperature $T_{\mathrm{N}}$ of the $\mathrm{P}_{\mathrm{s}}$ curve nose; minimum incubation times $t_{N}$ and $t_{N}^{\prime}$ for $P_{s}$ and $P_{f}$ curves, respectively; static recrystallization critical temperature (SRCT).

\begin{tabular}{|c|c|c|c|c|c|c|c|}
\hline Steel & $\varepsilon$ & $t_{\mathrm{N} 1}, \mathrm{~s}^{*}$ & $\mathrm{t}^{\prime}{ }_{\mathrm{N} 1}, \mathrm{~s}^{*}$ & $\mathrm{t}_{\mathrm{N} 2}, \mathrm{~s}^{* *}$ & $\mathrm{t}^{2}{ }_{\mathrm{N} 2}, \mathrm{~s}^{* *}$ & $\mathrm{~T}_{\mathrm{N},}$ & $\mathrm{SRCT}$, \\
$\mathrm{K} 3$ & 0.20 & 26 & 460 & - & - & $1238(965)$ & $1293(1020)$ \\
\hline $\mathrm{N} 3$ & 0.35 & 15 & 200 & - & - & $1218(945)$ & $1275(1002)$ \\
\hline $\mathrm{N} 4$ & 0.20 & 11 & 38 & 80 & 230 & $1295(1022)$ & $1338(1065)$ \\
\hline $\mathrm{N} 4$ & 0.35 & 8 & 23 & 42 & 130 & $1278(1005)$ & $1320(1047)$ \\
\hline
\end{tabular}

* subindex $\mathrm{I}$ : it is referred to the first plateau

*** subindex 2: it is referred to the second plateau, only in steel N4.

viously mentioned minimum incubation time $\left(t_{\mathrm{N}}\right)$, the minimum time of the end of precipitation $\left(t_{\mathrm{N}}^{\prime}\right)$, the temperature of the nose of the curve $\left(T_{\mathrm{N}}\right)$, the time which precipitation lasts $\left(t_{\mathrm{N}}^{\prime}-t_{\mathrm{N}}\right)$ and finally SRCT. The values of the minimum incubation time $\left(t_{\mathrm{N}}\right)$, and of the curve nose temperature $\left(T_{N}\right)$, are shown in Table 4 . In the case of steel N4, the values of $t_{\mathrm{N}}$ and $t_{\mathrm{N}}^{\prime}$ have been noted for the two precipitations, it being seen that the second precipitation has a relatively long incubation time and very slow recrystallization kinetics, expressed by the difference $t_{\mathrm{N} 2}^{\prime}-t_{\mathrm{N} 2}$, in comparison with the first precipitation.

The minimum incubation time decreases as the strain increases. However, the effect of the strain has been less for steel $\mathrm{N} 4$, where $t_{\mathrm{N}}$ has changed from $11 \mathrm{~s}$ for the strain of 0.20 to $8 \mathrm{~s}$ for the strain of 0.35 , while in steel $\mathrm{N} 3$ the variation has been from $26 \mathrm{~s}$ to $15 \mathrm{~s}$. This fact was already known ${ }^{30)}$ in low carbon microalloyed steels $(\mathrm{C}=0.1 \mathrm{mass} \%)$ and the results obtained in this study confirm previous results and make it possible to establish a greater generalization of these.

RPTT diagrams can be used to better understand the recrystallization-precipitation interaction (R-P) and to modify classic rolling schedules or establish new schedules. For instance, strain induced precipitation takes place at temperatures between SRCT and $T_{\mathrm{N}}$, as at temperatures below the latter the nucleation times grow rapidly due to the low diffusion of precipitate forming elements, though the saturation of austenite is greater.

Another of the possibilities offered by knowing the RPTT diagrams would be to know whether the chemical composition of the steel, especially with regard to precipitate forming elements, is adequate to ensure that coalescence of the precipitates is avoided in the hot rolling mill. Interpass times in the finishing mill are short, around $3 \mathrm{~s}$, and it would be convenient for the strain applied in each pass to be sufficient to produce precipitation, avoiding by means of the adequate subsequent cooling the coalescence of precipitates.

On the other hand, it would be possible to avoid strain induced precipitation by finishing rolling at temperatures above SRCT, as according to Figs. 5-8, if rolling finishes in these conditions, the austenite is totally recrystallized and the $P_{s}$ curve would not serve as a reference. In these conditions precipitation would occur during the austenite/ferrite transformation, preventing the coalescence of the precipitates due to the low temperatures. This does not mean that this type of rolling is the most appropriate, as in this case the ferrite grain size obtained would be smaller. Nevertheless, it is a possibility to be taken into account in medium or high carbon steels.

SRCT appears to be the asymptote of the $P_{s}$ and $P_{f}$ curves, representing a great help for their plotting. In the case of steel N4, the SRCTs of the two precipitations are somewhat different and have been determined using a new method described in the following section.

\subsection{Static Recrystallization Critical Temperature (SRCT)}

From the RPTT diagrams we determined the coordinates of the intersection points of the lines of different recrystallized fractions with the $P_{s}$ curve, giving the temperature at which precipitates start to form for each of the recrystallized fractions. A graphic representation of the recrystallized fraction against these temperatures and extrapolation to the fraction equal to unity made it possible to determine the SRCT. When deformation takes place in isothermal conditions, as in the torsion tests which were performed, precipitation only depends on time and it is not necessary to reduce the temperature for it to progress. Therefore, SRCT is defined as the temperature at which precipitation starts and finishes when the recrystallized fraction is $100 \%$.

SRCT should not be confused with the no-recrystallization temperature $\left(T_{\mathrm{nr}}\right)$, as though in some cases they can coincide, the concepts are somewhat different and thus their values also differ. On the one hand, $T_{n r}$ is determined by simulation of several rolling steps and its value for a certain steel depends on the strain, strain rate and interpass time. ${ }^{31)}$ With regard to this last variable, its value in microalloyed steels passes through a minimum, which occurs at an interpass time between $10-15 \mathrm{~s}$, and subsequently increases again. ${ }^{31)}$ If we observe the RPTT diagrams in Figs. 5-8, it can easily be seen that if the interpass time in the rolling simulation is long, both magnitudes would coincide. But if the interpass time is less, e.g. lower than $10 \mathrm{~s}, T_{\mathrm{nf}}$ would be greater than SRCT, as the recrystallized fraction would not be complete and furthermore in this case it would be in the no-precipitation zone as really occurs. When the interpass time is relatively long, both magnitudes coincide.

Figure 9 shows this representation for steel N3, finding SRCT values of 1020 and $1002^{\circ} \mathrm{C}$ when the strain was 0.20 and 0.35 , respectively. Thus, an increase in the strain causes a reduction in the value of SRCT and though in principle this may seem a little strange, it should not be forgotten that though an increase in the strain causes the consequent increase in the density of dislocations and therefore of sites for the nucleation of precipitates, it is also true that recrystallization would be faster and therefore the final balance would be a net reduction of nucleation sites.

The determination of SRCT for steel N4 is shown in Fig. 10, where slight differences can be seen between the values of this magnitude for the two types of 


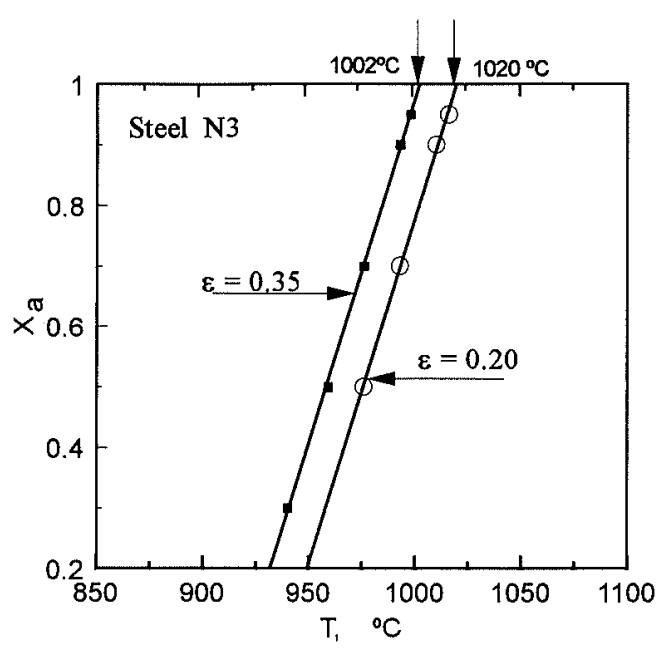

Fig. 9. Recrystallized fraction $\left(X_{\mathrm{a}}\right)$ against the temperature of intersection between the recrystallized fraction lines and $\mathrm{P}_{\mathrm{s}}$ curve for steel $\mathrm{N} 3$.

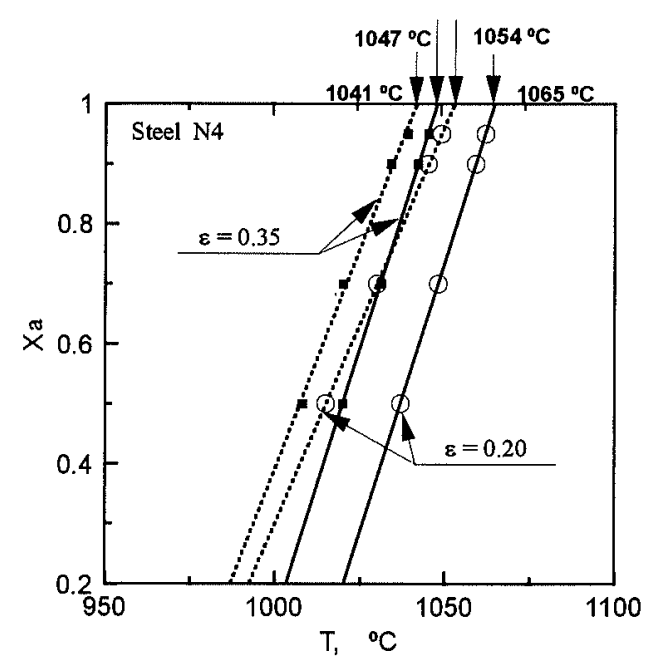

Fig. 10. Recrystallized fraction $\left(X_{\mathrm{n}}\right)$ against the temperature of intersection between the recrystallized fraction lines and $\mathrm{P}_{\mathrm{s}}$ curve for steel $\mathrm{N} 4$.

precipitation. The values thus determined for the two steels are shown in Table 4, except for those which correspond to the second precipitation in steel $\mathrm{N} 4$, which are of lesser importance.

Finally, the values of SRCT help to draw good RPTT diagrams, as the horizontal line of this value must be an asymptote of the $P_{s}$ and $P_{f}$ curve.

\subsection{Activation Energy $(Q)$}

Activation energy is an important parameter in static recrystallization kinetics, not only because its value depends on the chemical composition, and thus can be considered a parameter intrinsic to the material, but also because its value would indicate the relative difficulty with which the different alloying elements contribute to self-diffusion at the grain boundaries. ${ }^{11)}$

The activation energy can be easily determined from Figs. 1-4. In accordance with Eq. (2), Figs. 11 and $\mathbf{1 2}$ show the parameter $t_{0.5}$ against the inverse of the absolute temperature for the steels $\mathrm{N} 3$ and $\mathrm{N} 4$, respectively, it being possible to appreciate the two stages corresponding to temperatures above and below SRCT.

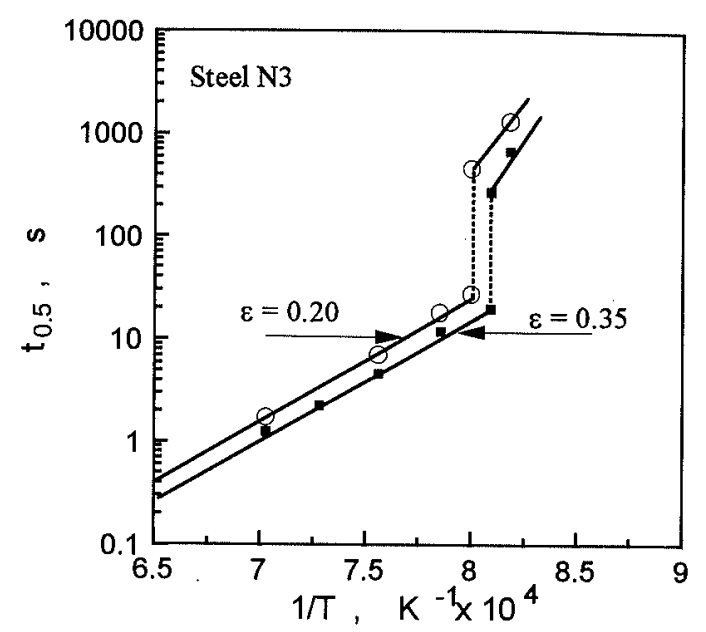

Fig. 11. Plot of $t_{0.5}$ against the reciprocal of the absolute temperature for steel $\mathrm{N} 3$.

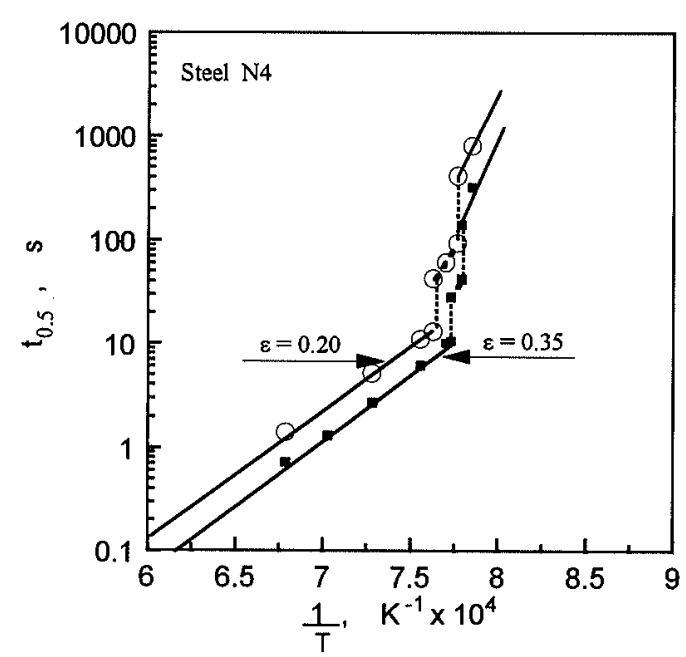

Fig. 12. Plot of $t_{0.5}$ against the reciprocal of the absolute temperature for steel $\mathrm{N} 4$.

In the case of steel N3 (Fig. 11), the function $\ln t_{0.5}$ against $1 / T$ shows a discontinuity not only in that which is derived, but also in the function itself, just when the temperature reaches the value of SRCT. The jump between stages takes place in an interval of time which coincides with the interval $\mathrm{P}_{\mathrm{f}}-\mathrm{P}_{\mathrm{s}}$ close to the nose. The slope of each plot multiplied by the universal gas constant $(R)$ gives the value $Q$, before and after precipitation. In the first stage, $Q$ was $230000 \mathrm{~J} / \mathrm{mol}$, and in the second stage, after precipitation, the activation energy was $555000 \mathrm{~J} / \mathrm{mol}$. In other words, the value of the activation energy changes from one stage to another and this occurs at a constant temperature during the time in which precipitation takes place $\left(\mathrm{P}_{\mathrm{f}}-\mathrm{P}_{\mathrm{s}}\right)$. After precipitation, the activation energy increases significantly, which is obviously translated into a greater difficulty for the austenite to recrystallize.

With regard to steel N4 (Fig. 12), three values can be calculated for activation energy because of the double precipitation. For temperatures above SRCT of the first precipitation, i.e. when all the elements are in solution, the value of $Q$ found was $245000 \mathrm{~J} / \mathrm{mol}$. After the first precipitation, in the small range of temperatures prior to the second precipitation, the value of $Q$ determined 


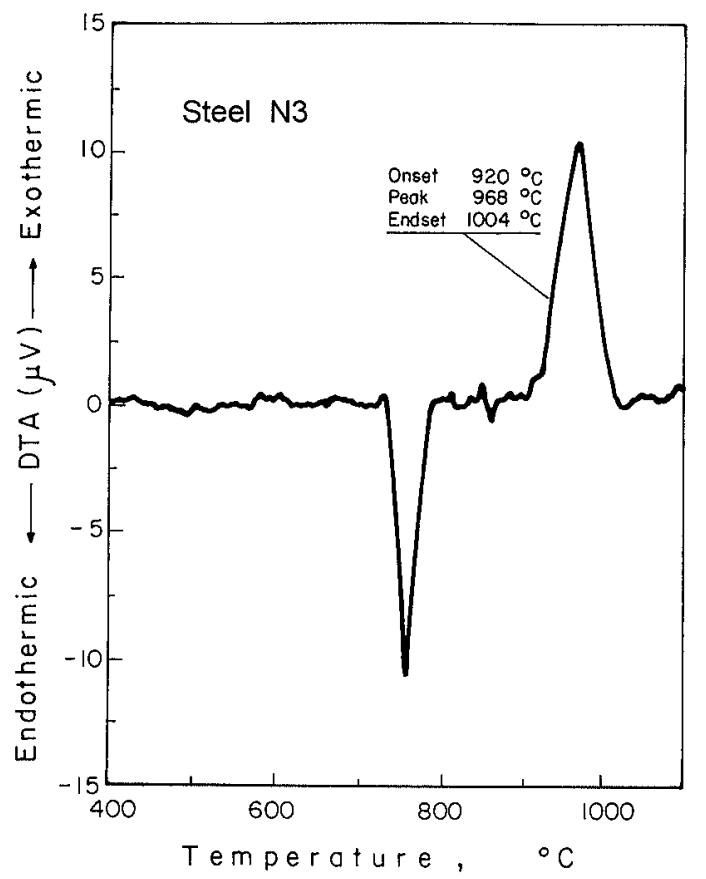

Fig. 13. Differential thermal analysis (DTA) curves for steel N3.

was $472000 \mathrm{~J} / \mathrm{mol}$. Finally, after the second precipitation, the activation energy was $626000 \mathrm{~J} / \mathrm{mol}$. Comparison of the different values indicates that the second precipitation contributes notably to increasing the difficulties of the recrystallization kinetics and that it is not a pseudoprecipitation.

From the activation energy values it is deduced that $\mathrm{Nb}$, even in solution, notably contributes to delaying recrystallization kinetics, if the values found are compared with those corresponding to C-Mn type steels or $\mathrm{V}$ microalloyed steels. ${ }^{11,12)}$

\subsection{Differential Thermal Analysis}

The DTA curve corresponding to steel N3 (Fig. 13) shows two reactions. The one which occurs at a lower temperature, of endothermic nature, is the phase transformation of pearlite and ferrite into austenite, and the one which occurs at a high temperature, exothermic, is precisely the dissolution of the precipitates. The start and end temperatures of the dissolution of the precipitates are noted in the same figures, along with the corresponding peak temperature.

In the case of steel N4 (Fig. 14), the presence was seen of two exothermal reactions, corresponding to the dissolution of the precipitates. Comparison of the final temperatures of each reaction with the calculated solubility temperatures for niobium nitrides and carbides ${ }^{2)}$ does not clearly show, at least not definitively, the nature of the precipitates. Nevertheless, it seems obvious that there is a dissolution of two types of precipitates, corresponding to the formation of the two peaks respectively.

Both for steel N3 and steel N4, the final temperatures of the exothermal reactions do not coincide with the solubility temperatures of nitrides, carbides or carbonitrides, respectively. This is due to the fact that the precipitate formation conditions were not the conditions

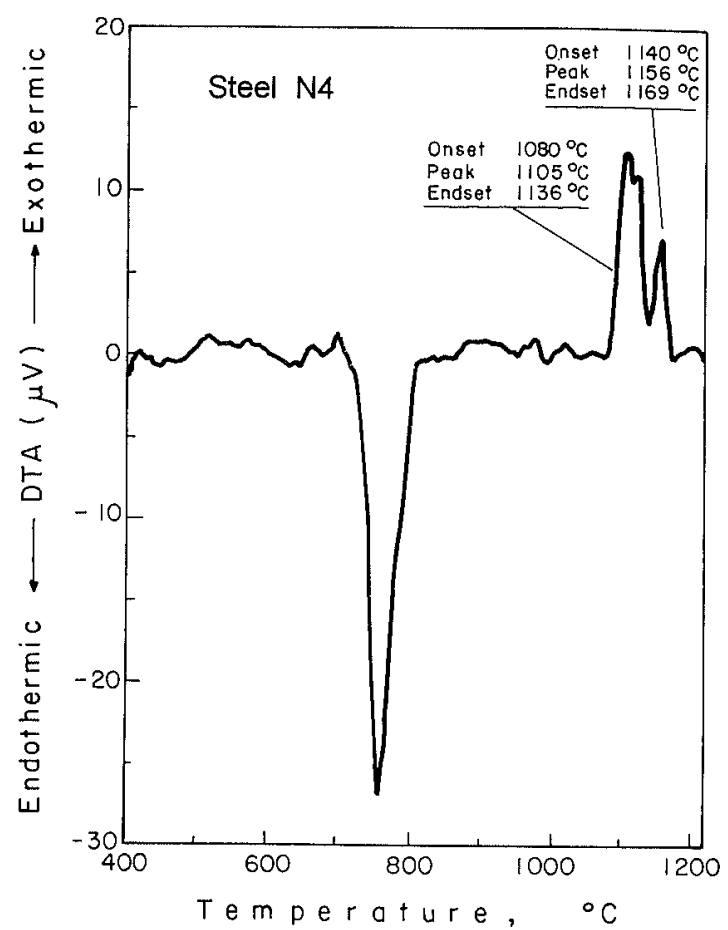

Fig. 14. Differential thermal analysis (DTA) curves for steel N4.

of balance and furthermore the formation of the second type of precipitates would part from initial amounts of $\mathrm{C}, \mathrm{N}, \mathrm{Nb}$ in solution different to their total contents, due to the fact that they would obviously be shared between the two precipitate kinds, as it seems can be deduced from the two transformations. From the differential thermal analysis it is obviously not possible to deduce what percentages of niobium have been distributed between nitrides and carbides and therefore it is not possible to compare the solubility temperatures with the final temperatures of the two transformations. Thus, it cannot be stated with complete certainty that the precipitates are carbonitrides only and that there is not a presence of some nitrides and carbides.

\subsection{Precipitates: Size and Distribution}

Observation of the precipitates was carried out on the same specimens deformed and quenched to observe the recrystallized fraction of the austenite. Observations were made for the two specimens tested of the steel N3 at $1000^{\circ} \mathrm{C}$, strain of 0.35 and recrystallization times of 30 and $200 \mathrm{~s}$. From the curve of the recrystallized fraction at $1000^{\circ} \mathrm{C}$ in Figure 2, it is seen that the times selected were close to the start and finish of the inhibition of recrystallization, respectively. In the specimen tested at $30 \mathrm{~s}$, where the resolution of precipitates by TEM is shown in Fig. 15a), the study of the distribution of sizes, carried out on a population of more than one hundred precipitates, indicated a classic lognormal distribution with an average particle diameter of $51.14 \mathrm{~nm}$ and a greater frequency for an approximate size of $10 \mathrm{~nm}$ (Fig. 15b)). The geometry of the particles was in general rounded and also lengthened forms were observed .

The electron energy dispersive X-ray spectrum showed the presence of $\mathrm{Nb}$ and the lattice parameter determined from electron diffraction image revealed a f.c.c. cubic 
a)
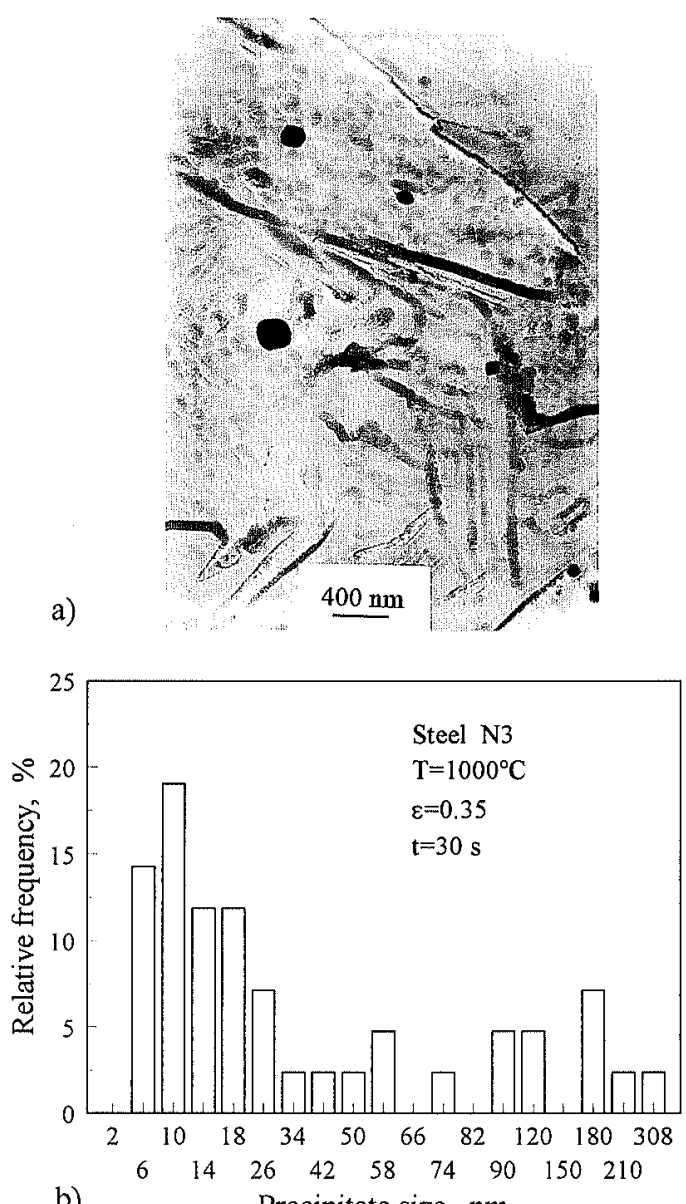

b)

Precipitate size, $\mathrm{nm}$

Fig. 15. TEM image of steel $\mathrm{N} 3$ for sample tested at $1000^{\circ} \mathrm{C}$; $\varepsilon=0.35 ; t=30 \mathrm{~s}$. a) precipitates; b) relative frequency of precipitate size.

lattice with a value of $a=4.536 \AA$, which is identified, in accordance with the reference value found in the literature as a niobium carbide or carbonitride. ${ }^{32)}$

Figure 16a) displays the precipitates at $200 \mathrm{~s}$ after deformation. The study of distribution of precipitates indicated two populations, one of fine particles centred around an average particle diameter of $18 \mathrm{~nm}$ and another of coarser particles with an average diameter of $180 \mathrm{~nm}$. So, the precipitates presented a bimodal character in the distribution of sizes, as is shown in the diagram in Fig. 16b).

With regard to steel $\mathrm{N} 4$, three specimens were tested at $1025^{\circ} \mathrm{C}$, strain of 0.35 and holding times of 15,50 and $100 \mathrm{~s}$. Figure 4 shows that the selected times were subsequent to the start of the first plateau, coinciding with the start of the second and during the second platform, respectively. The morphology of the precipitates was similar to that of the previous steel (Fig. 17a)) and the distribution of precipitates was also of the same characteristics, i.e. for the time of $15 \mathrm{~s}$ a lognormal distribution was obtained with an average particle diameter of $34.88 \mathrm{~nm}$, the greater frequency corresponding to a particle diameter of $18 \mathrm{~nm}$ (Fig. 17b)). For longer times, the distribution was bimodal. In the case of the time of $50 \mathrm{~s}$, the greater frequency referring to the finer precipitates corresponded to an average particle size of $18 \mathrm{~nm}$ and for the coarser precipitates the greatest a)
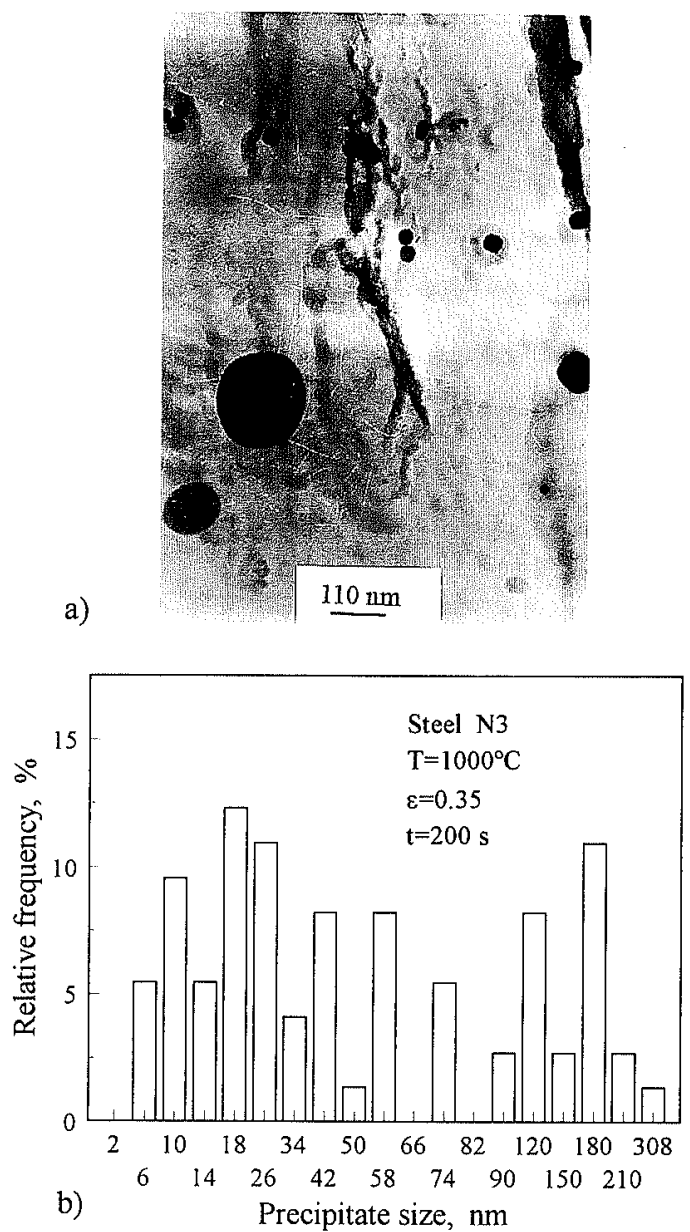

Fig. 16. TEM image of steel $\mathrm{N} 3$ for sample tested at $1000^{\circ} \mathrm{C}$; $\varepsilon=0.35 ; t=200 \mathrm{~s}$. a) precipitates; b) relative frequency of precipitate size.

frequency corresponded to an average size of $180 \mathrm{~nm}$ (Fig. 18a)). Furthermore, for the time of $100 \mathrm{~s}$, the maximum frequencies were $26 \mathrm{~nm}$ and $140 \mathrm{~nm}$, for the finer and coarser precipitates, respectively (Fig. 18b)).

The precipitate coarsening can be explained by the modified Lifshitz-Slyozov-Wagner theory (MLSW). ${ }^{33)}$ The last theory predicts that while the basic $t^{1 / 3}$ kinetics of the LSW theory is maintained, the coarsening rate increases with increasing volume fraction, even at very small values of precipitate volume fraction. According to the MLSW theory, the theoretical distribution of particle sizes broadens rapidly at the small values of volume fraction. This theory has been checked by observing that even for short times, close to the start of precipitation, the average size of the precipitates increased not only due to heterogeneous nucleation but also to the coalescence between the precipitates, a phenomenon which has been observed in some micrographs such as that shown in Fig. 19, where the image seems to show how two precipitates have combined by controlled diffusion (Oswald ripening) to form a precipitate of greater size, identified as the precipitate situated in the centre of the micrograph.

It is deduced from the above results that the first precipitates to nucleate present a lognormal distribution with a maximum frequency corresponding to a precipitate size between $10-15 \mathrm{~nm}$, which will depend in 
a)
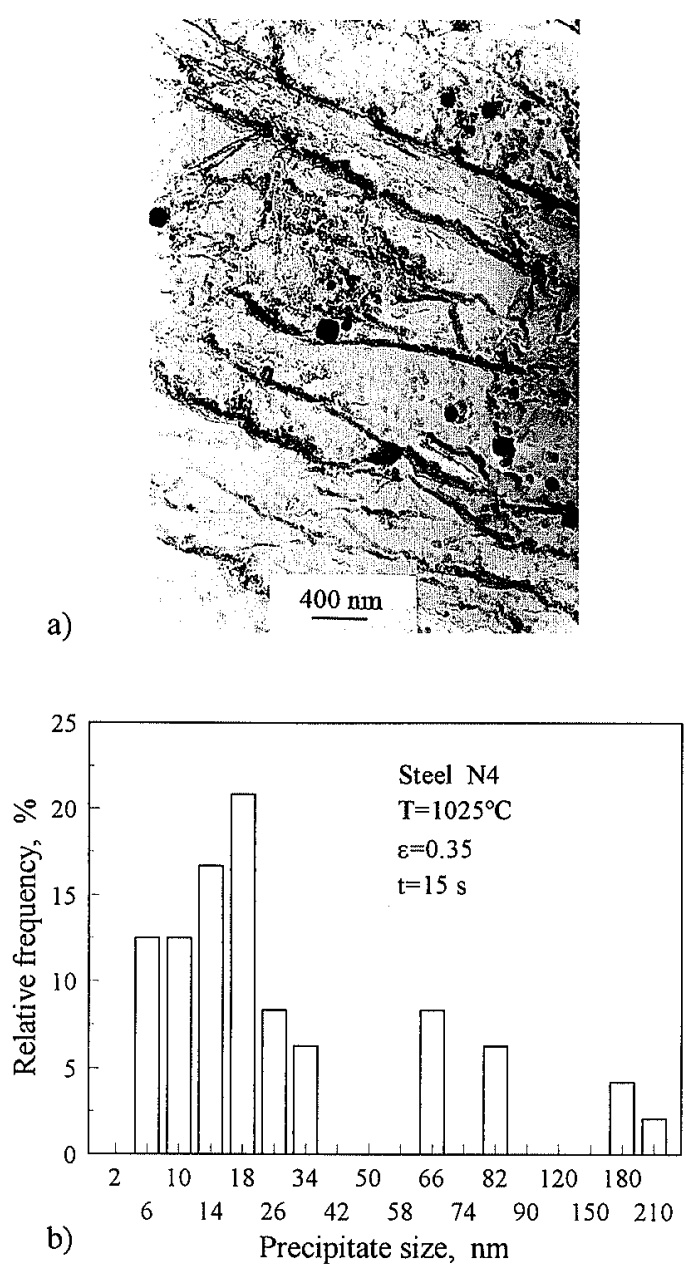

Fig. 17. TEM image of steel $\mathrm{N} 4$ for sample tested at $1025^{\circ} \mathrm{C}$; $\varepsilon=0.35 ; t=15 \mathrm{~s}$. a) precipitates; b) relative frequency of precipitate size.

turn on the $\mathrm{Nb}$ content and on the temperature. These fine precipitates are responsible for the inhibition of re crystallization. At the end of the plateau the distribution of precipitates is bimodal, but it can still be seen that the frequency of fine precipitates is still important and they are responsible for the fact that recrystallization is still inhibited. In the two steels it was observed that at the end of the plateau the maximum frequency of the fine precipitates corresponded to a size close to $20 \mathrm{~nm}$, a size which could be considered as critical for inhibiting recrystallization, i.e. that the driving forces and pinning forces exerted by the precipitates are of equal magnitude.

The above results coincide with those of other authors $^{34)}$ in which the start of the plateau is identified with the start of precipitation. However, the same authors established that the end of the hump, a figure that was formed due to the fact that they measured the softened fraction and not the recrystallized fraction, did not coincide with the end of precipitation, corresponding to a longer time. This difference may possibly be due to the fact that the end of the hump does not appear well defined and nevertheless the end of the plateau and its subsequent transformation in the $P_{f}$ curve appears to be very clearly defined.

Finally, with the intention of enriching the discussion
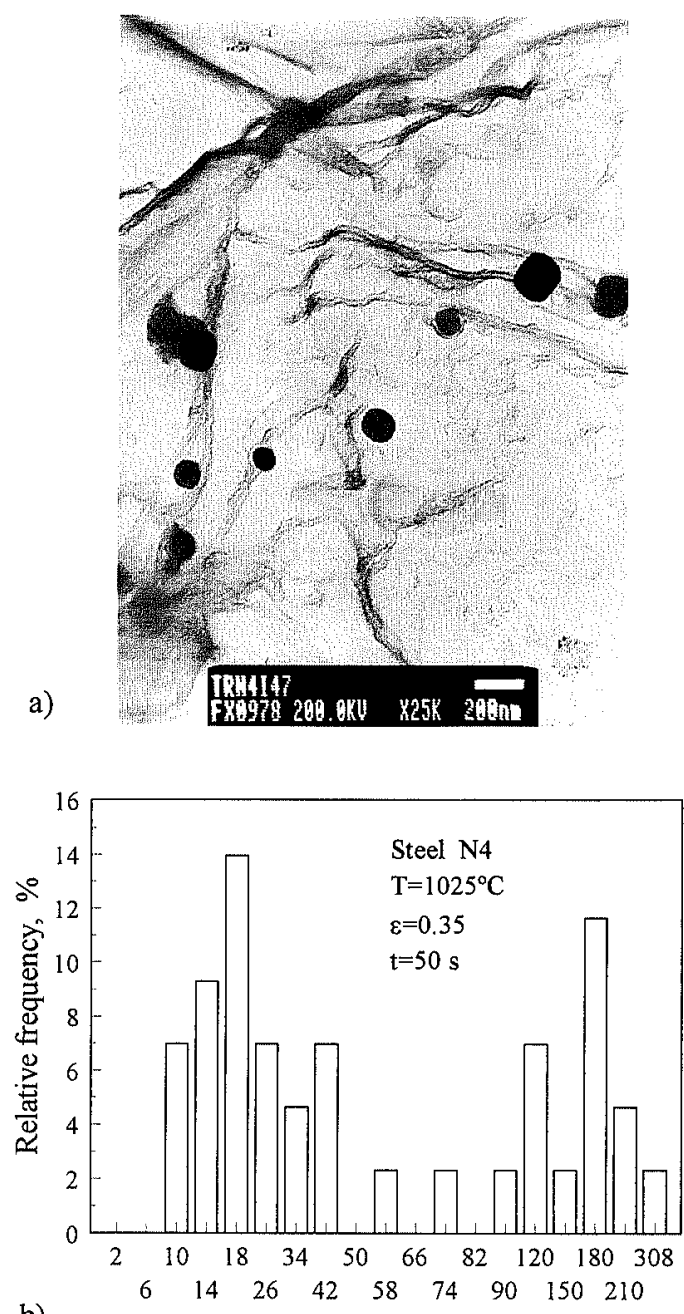

b)

Precipitate size, $\mathrm{nm}$

Fig. 18. TEM image of steel $\mathrm{N} 4$ for sample tested at $1025^{\circ} \mathrm{C}$; $\varepsilon=0.35 ; t=50 \mathrm{~s}$. a) precipitates; b) relative frequency of precipitate size.

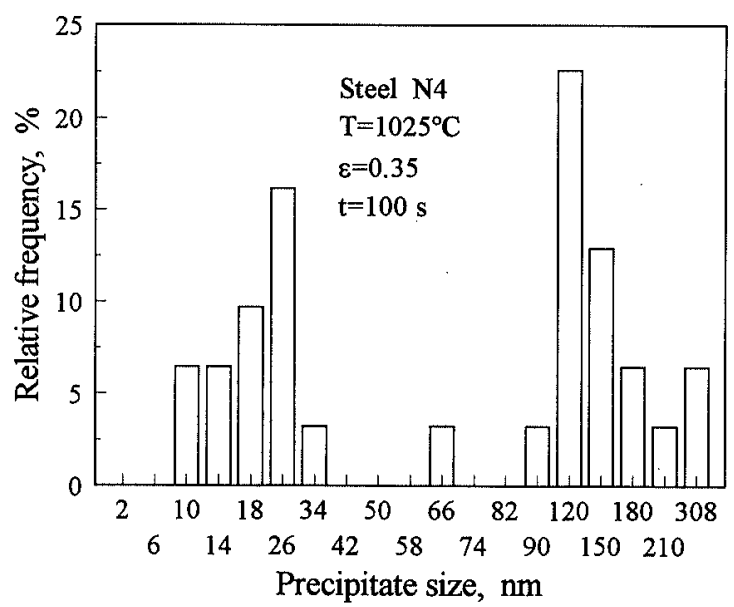

Fig. 19. Relative frequency of precipitate size in steel $\mathrm{N} 4$ for sample tested at $1025^{\circ} \mathrm{C} ; \varepsilon=0.35 ; t=100 \mathrm{~s}$

of the results, it should be said that a general model for recrystallization kinetics, applicable to low alloy and microalloyed steels, and thus to the steels studied, has been published. ${ }^{1-131}$

\section{Conclusions}

The method which is developed permits the determina- 


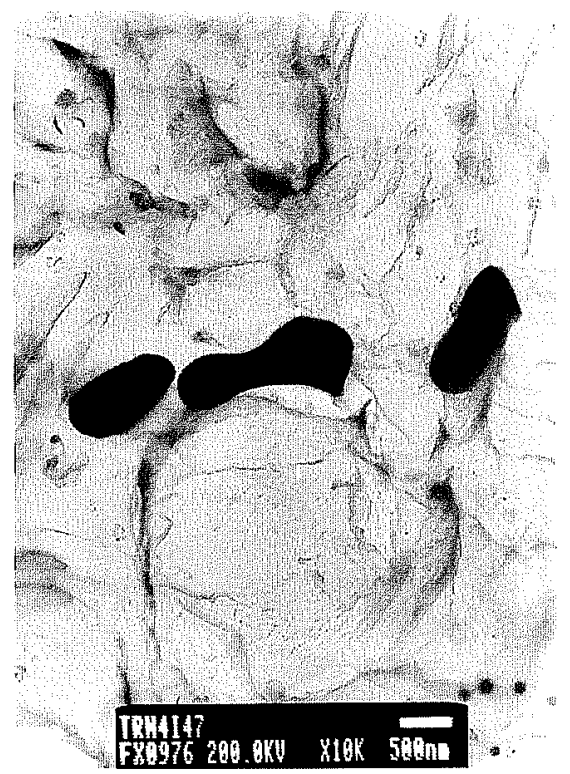

Fig. 20. TEM image showing precipitate coalescence. Steel N4 for sample tested at $1025^{\circ} \mathrm{C} ; \varepsilon=0.35 ; t=50 \mathrm{~s}$.

tion of RPTT diagrams, the static recrystallization critical temperature (SRCT) and the recrystallization-precipitation interaction. These aspects were studied in two steels with an identical $\mathrm{C}$ content $(0.21$ mass $\%)$, approximately equal $\mathrm{N}$ content $(0.0058$ and $0.0061 \mathrm{mass} \%)$ and different $\mathrm{Nb}$ contents $(0.024$ and 0.058 mass $\%)$. From the results, and the above discussion, certain conclusions can be drawn.

(1) While steel $\mathrm{N} 3$ presented a single plateau for recrystallized fraction $\left(X_{\mathrm{a}}\right)$ against time at temperatures below $1000^{\circ} \mathrm{C}$ and for strains of both 0.20 and 0.35 , steel $\mathrm{N} 4$, which has a higher $\mathrm{Nb}$ content, presented two plateaus corresponding to two different precipitations of complex carbonitrides.

(2) In the two steels, at greater strains, the times for incubation and complete precipitation are smaller.

(3) As a consequence of the higher $\mathrm{Nb}$ content in steel N4, the influence of strain on the incubation time was less in this steel than in steel N3.

(4) For the minimum incubation time, at the "nose" of the $P_{s}$ curve, the recrystallized fraction is approximately equal to 0.5 . When the fraction is less than 0.5 the incubation time becomes increasingly longer, and when the fraction reaches values even lower than 0.3 nucleation of the precipitates is practically impossible.

(5) Activation energy changes at SRCT, being much greater after precipitation, which is translated into a greater difficulty for the austenite to recrystallize. In particular, after the second precipitation in steel N4, the activation energy experiences an increase compared with that which it had experienced when the first precipitation took place.

(6) In both steels, the distribution of precipitate sizes is lognormal when precipitation starts, with a maximum frequency corresponding to sizes between $10-15 \mathrm{~nm}$, probably depending on the content of microalloying element and on the temperature.

(7) As the precipitation kinetics progresses, the log- normal distribution becomes converted into a bimodal distribution. At the end of precipitation, the greatest frequency of fine precipitates corresponds to an average size of approximately $20 \mathrm{~nm}$, which can be considered as critical or maximum for inhibiting recrystallization.

\section{Acknowledgements}

The authors would like to thank the Interministerial Science and Technology Commission (CITYT) for the funding granted to project MAT 94-0798, and the Institute of Iberoamerican Cooperation (ICI) for financing the stay in CENIM of Eng. A. Quispe.

\section{REFERENCES}

1) K. Narita: Trans. Iron Steel Inst. Jpn., 15 (1975), 145.

2) E. T. Turkdogan: Iron Steelmaker, 16 (1989), 61.

3) P. R. Rios: Mater. Sci. Technol., 4 (1988), 324.

4) E. J. Palmiere, C. I. García and A. J. DeArdo: Metall. Trans., 25A (1994), 277.

5) C. M. Sellars, Proc. Int. Conf. on Hot Working and Forming Processes, Ed. by C. M. Sellars and G. J. Davies, Met. Soc., London, (1980), 3.

6) S. Yamamoto, C. Ouchi and T. Osuka: Int. Conf. on Thermomechanical Processing of Microalloyed Austenite, ed. by A. J. DeArdo, G. A. Ratz and P. J. Wray, Metall. Soc., AIME, Pensylvania, (1982), 613.

7) A. Laasraoui and J.J. Jonas: Metall. Trans., 22A (1991), 151.

8) G. Li, T.M. Maccagno, D. Q. Bai and J.J. Jonas: ISIJ Int., 36 (1996), 1479.

9) S.F. Medina: Scripta Metall. Mater., 32 (1995), 43.

10) L. P. Kajalainen, T. M. Maccagno, J. J. Jonas: ISIJ Int., 35 (1995), 1523.

11) S. F. Medina and J. E. Mancilla: ISIJ Int., 36 (1996), 1063.

12) S. F. Medina and J. E. Mancilla: ISIJ Int., 36 (1996), 1070.

13) S. F. Medina and J. E. Mancilla: ISIJ Int., 36 (1996), 1077.

14) M. J. Luton, R. Dorvel and R.A. Petkovic: Metall. Trans., 11A (1980), 411 .

15) S. F. Medina: J. Mater. Sci., 31 (1997), 1487

16) A. Quispe, S. F. Medina, and P. Valles: ISIJ Int., 37 (1997), 783.

17) B. Dutta and C.M. Sellars: Mater. Sci. Technol., 3 (1987), 197.

18) S. Okaguchi and T. Hashimoto: ISIJ Int., 32 (1992), 283.

19) S. H. Park, S. Yue and J. J. Jonas: Metall. Trans., 23A (1992), 1641 .

20) D. Q. Bai, S. Yue, W. P. Sun and J. J. Jonas: Metall. Trans., 24A (1993), 21 51

21) W. P. Sun, M. Militzer, D. Q. Bai and J. J. Jonas: Acta Metall. Mater., 41 (1993), 3595.

22) A. Le Bon, J. Rofes-Vernis and C. Rossard: Met. Sci.,9(1975), 36.

23) W. J. Liu and J. J. Jonas: Metall. Trans., 19A (I988), 1403.

24) W. J. Liu and J. J. Jonas: Metall. Trans., 20A (1989), 689.

25) S. F. Medina: Mater. Sci. Technol., 14 (1998), 217.

26) H. L. Andrade, M. G. Akben and J. J. Jonas: Metall. Trans., 14A (1983), 1967

27) P. Choquet, A. Le Bon and C. Perdrix: Proc. Int. Conf. on Strength of Metals and Alloys, CISMA 7, Ed. by H. J. Mcqueen, J. B. Bailon, J. I. Dickson, J. J. Jonas and M. G. Akben, Pergamon Press, Oxford, Vol. 3 (1986), 1205.

28) A. Quispe: Recrystallization-induced Precipitation Interaction Study in Microalloyed Steels, Doctoral Thesis, CENIM, Madrid, (1998).

29) Lifshitz and V. V. Slyozov: J. Phys. Chem. Solids, 19 (1961), 35.

30) S.F. Medina and A. Quispe: ISIJ Int., 36, (1996), 1295.

31) D. Q. Bai, S. Yue, W. P. Sun and J. J. Jonas: Metall. Trans., 24A (1993), 2151

32) T. Gladman: The Physical Metallurgy of Microalloyed Steels, The Institute of Materials, London, (1997).

33) A. J. Ardell: Acta Metall., 20 (1972), 61.

34) K. B. Kang, O: Kwon, W. B. Lee and C. G. Park: 37th MWSP Conf. Proc., Vol. XXXIII, ISS, Warrendale, PA, (1996), 689. 